\title{
Processo Coletivo de Aprendizagem e Inovação Territorial - Limites e Possibilidades de Desenvolvimento Local - Região do Imbirussú, Campo Grande-MS, 2008-2012
}

\author{
Collective Learning Process and Territorial Innovation - limits And Possibilities of \\ Local Development - Region Imbirussú, Campo Grande-MS, 2008-2012
}

\author{
Aparecida Cristina Campello Curado Piccolo ${ }^{1}$ \\ Maria Augusta de Castilho²
}

Artigo recebido para publicação em Ago/2013 e aceito para publicação em Ago/2013

\begin{abstract}
RESUMO
Investigar práticas educativas presentes no cotidiano escolar da Educação Básica e procurar concretamente articular a prática à teoria revelou-se campo fértil na construção de Projeto Político Pedagógico Escolar, pois tal prática favorece reflexões continuadas sobre as possibilidades e os limites presentes na educação escolar. No caso desta pesquisa, entre as interações: Escola Comunidade Escolar e Tecnologias Sociais, como potencialidades de Desenvolvimento Local. O universo selecionado para a pesquisa foi o da Escola Municipal Prof. Fauze Scaff Gattass Filho e sua comunidade escolar de entorno, localizada no Bairro Nova Campo na cidade de Grande-MS. O estudo foi pautado no método indutivo, com observações in loco e tendo como aporte teórico bibliográfico autores renomados que serviram de apoio para o desenvolvimento do presente artigo. As reflexões sobre tecnologias sociais e as ações do educador/educando, permeiam princípios pedagógicos que podem gerar a produção do conhecimento no âmbito escolar do Ensino Fundamental brasileiro.
\end{abstract}

Palavras-chave: Tecnologias Sociais. Território. Comunidade. Desenvolvimento local.

\begin{abstract}
Investigate educational practices in everyday school life of Basic Education and look specifically articulate practice to theory proved fertile ground in the construction of the Political Pedagogical School, as this practice encourages ongoing reflections on the possibilities and limitations present in school education. In this research, the interactions between: School - Community School and Social Technologies as potential local development. The universe selected for the survey was the Municipal School Professor. Fauze Scaff Gattass Son and his school community surroundings, located in New Town in the city of Campo Grande-MS. The study was guided by the inductive method with in situ observations and with the theoretical literature renowned authors that served as support for the development of this article. Reflections on social technologies and actions of the teacher / student permeate pedagogical principles that can generate the production of knowledge in schools of Basic Education in Brazil.
\end{abstract}

Keywords: Social Technologies. Territory. Community. Local development.

\footnotetext{
${ }^{1}$ Mestranda do Programa de Pós-Graduação em Desenvolvimento Local - mestrado acadêmico, desenvolvendo pesquisa na área de Tecnologia Social - Universidade Católica Dom Bosco. E-mail: caparecidacristina@yahoo.com.br

${ }^{2}$ Pós-doutora em Linguística e doutora em História Social, docente no Programa de Pós-Graduação em Desenvolvimento Local - mestrado acadêmico. Pesquisadora na área de Ciências Humanas (Patrimônio/Sagrado) da Universidade Católica Dom Bosco. E-mail: m.a.castilho@terra.com.br
} 


\section{INTRODUÇÃO}

Constata-se que no Brasil, os problemas de base estão ainda por serem resolvidos, e, portanto, diante de constantes transformações tecnológicas na conquista do conhecimento, convive-se simultaneamente, com analfabetismo, fome, desemprego, violência, sem condições de interação com perfis sociais mais justos e inclusivos. No âmbito da educação escolar, o desafio desta convivência apresenta questões mais específicas, entre tantas dificuldades, destaca-se o insucesso da escola existente em dialogar com sua comunidade; interna e externa. Pensar soluções para tais problemas passa pela questão da cidadania, entendida aqui, como participação crescente de cada cidadão na vida social, política e econômica do país.

Nessa perspectiva torna-se imprescindível a reflexão da relação entre educação popular e escola, com atenção especial ao papel desempenhado pela relação escola-comunidade do entorno, nas situações em que princípios da educação popular são incorporados nos Projetos Político-Pedagógicos das Redes do Ensino Público brasileiro

Foi na esteira da reflexão sobre esta experiência que se objetivou investigar o propósito assumido por um conjunto de atores, que em dado ambiente escolar decidiu-se por colocar em prática um projeto acordado na busca de fins específicos, impregnados pela própria cultura.

Assim, a pesquisa teve como objetivo principal implantar em uma escola pública de periferia um projeto pedagógico que envolvesse a comunidade do entorno, que por meio de uma parceria ativa pudesse compartilhar com alunos e professores a melhoria da qualidade de ensino via novas formas de saberes e aprendizagem, inclusive utilizando novas tecnologias. Nesse contexto algumas questões norteadoras orientaram o processo de investigação, tais como: no exercício da experiência existe unidade entre teoria e prática? Quais os principais limites e possibilidades de Desenvolvimento Local detectados? Houve interação de diversas dimensões da Educação: Popular, Ambiental, Patrimonial? A articulação com as Tecnologias Sociais podem favorecer a construção de um processo de transformação social, em função do uso de capacidades e competências humanas na adaptação de recursos disponíveis a fins previamente definidos coletivamente? 
Aponta-se como questão principal - Como superar as "mazelas" e "feridas sociais" pré-existentes no modelo territorial já constituído? Como desenvolver processos coletivos de aprendizagem e inovação territorial?

Foram muitos os caminhos percorridos em discussões, reflexões e vivência ao longo do processo de pesquisa, visto que são muitos os desafios, tensões e dilemas a serem transpostos em processos de interação escola-comunidade na realidade social atual.

A insistência nessa temática não deixa de reconhecer a crise pela qual passa a educação, principalmente a pública, mas concebe a crise como fruto da disputa de interesses entre os diferentes e, às vezes antagônicos, grupos sociais, expressão, portanto, da própria correlação de forças existentes na sociedade.

Para responder as questões o estudo compreende revisão da literatura de vários autores, abordando temáticas relacionadas aos propósitos desta pesquisa, o que permitiu uma ampla visão de diversos conceitos fundamentais para reflexões e debates da temática proposta.

Quanto aos procedimentos técnicos da pesquisa inicialmente foram realizadas pesquisa bibliográfica de autores que embasaram a temática, seguida de reuniões formais e informais: escola, comunidade e órgãos de fomento (que financiaram as ações), por meio de uma pesquisa ação participativa, com o desenvolvimento de diversas atividades, envolvendo pesquisa de campos, oferecendo resultados reais sobre a população alvo do estudo.

\section{REDE DE SABERES COM POTENCIALIDADES DE DESENVOLVIMENTO LOCAL}

Nesse contexto, insere-se o Desenvolvimento Local, um modelo de desenvolvimento, capaz de agenciar e gerenciar o aproveitamento dos potenciais próprios.

Com base nos conceitos propostos por Ávila (2000), a cultura enquadra-se nas especificidades, nos potenciais internos das comunidades, a qual se destaca como o diferenciador.

A cidadania poderá não passar de figura de retórica se não relacionada com o território, evoca, Santos (1993), ao sugerir que o cidadão é o indivíduo num lugar. 
O Desenvolvimento Local não se reduz a analgésico socioeconômico de camadas periféricas, carentes e pobres desta ou daquela determinada localidade, mas sim, nos países em desenvolvimento, onde há a interatividade humana espacial. Isso, por se tratar de nova filosofia - política de desenvolvimento situado ou definido (ou que costumeiramente se denomina "comunidade"), com todas as circunstancialidades que Ihes sejam próprias, inclusive todas as riquezas, pobrezas, facilidades reais ou potenciais.

Portanto, o Desenvolvimento Local atua para que o contingente humano se torne capaz, competente e hábil de se despertar (sensibilizar), mobilizar, organizar, prover meios e tomar iniciativas, a fim de que paulatinamente os atores comunitários possam assumir a condição de sujeitos de implementação dos respectivos processos de desenvolvimento - comunitário - local endógeno (ÁVILA, 2000).

Nóvoa (1992, p. 20) explica que:

Não significa, todavia, que as comunidades locais se isolem em relação aos processos exteriores ou de âmbito nacional: pelo contrário, as interações com o meio envolvente tenderão a reforçar-se, no quadro de internalização (ou de uma localização desses processos. O desenvolvimento endógeno tende a apropriar-se dos contributos dos atores e a configurá-los no contexto local, dando-lhes uma forma específica e adaptada às características e as necessidades das populações).

As potencialidades provocadas e estimuladas necessitam, portanto, de modelos e de apoio externos, mas são de conhecimento que passam por transformações, mudanças, adaptações, inerentes às capacitações natas dos moradores e de suas lideranças, sempre objetivadas pelas necessidades locais.

Uma ação integrada e sustentável, também pode ser alcançada por meio de modelos e apoio externo adequados ao local, pela inovação, criação de um modelo inédito, pela criação de um modelo próprio de um determinado local ou comunidade, onde as potencialidades sejam provocadas e estimuladas. Isso, não deve impedir de forma nenhuma a sua integração com o externo, fazendo o intercâmbio de conhecimento ou de comércio, buscando atender os interesses locais.

A comunidade, com uma visão extremamente participativa e inteirada de suas dificuldades pode ao mesmo tempo em que emerge de um sentimento forte de união e de interesse coletivo, visualizar o desenvolvimento local por meio das suas potencialidades e oportunidades, e pode ainda, ser motivada por fatores tanto endógenos quanto exógenos, gerando frutos de reflexão e agregando experiências sui generis. 
Pouco adiantará combater a desigualdade social se as ações da Assistência Social não estiverem embasadas na cultura local. $O$ fortalecimento e a mobilização da cultura local podem exercer papel fundamental no sucesso das políticas e projetos voltados para a superação do estado de pobreza e exclusão social de populações marginalizadas.

Por outro lado, o espaço é formado por um conjunto indissociável, solidário e também contraditório de sistemas de objetos e sistemas de ações.

Nas palavras de Raffestin (1993, p. 143-144), espaço e território não são termos equivalentes, por isso:

\begin{abstract}
É essencial compreender que o espaço é anterior ao território. O território se forma a partir do espaço, é resultado de uma ação conduzida por um ator sintagmático (ator que realiza um programa) em qualquer nível. Ao se apropriar de um espaço, concreto ou abstratamente (por exemplo, pela representação), o ator 'territorializa' o espaço. [...] o território, nessa perspectiva, é um espaço onde se projetou um trabalho, seja energia e informação, e que, por consequência, revela relações marcadas pelo poder. O espaço é a 'prisão original', o território é a prisão que os homens constroem para si.
\end{abstract}

O território se constrói por e a partir de relações estabelecidas por um conjunto de indivíduos (atores), em um dado ambiente físico de referência (SOUZA, 1995). Para colocar em prática um projeto em comum e de acordo com o modelo espacial (RAFFESTIN, 1993), deve-se lançar mão da cultura nele impregnada e de conhecimento que os mesmos já detêm a respeito das atividades e dos objetos comunitários.

As relações de vizinhança, os deslocamentos cotidianos pelos diferentes lugares conhecidos e os pequenos atos corriqueiros no processo de vivência no território construído, propiciam a busca de significações, carregadas de afetividade, símbolos e emoções (CARLOS, 1996).

O conceito de território na visão de Santos (2002, p. 15) acrescenta novo paradigma à discussão, uma vez que para este autor:

É o uso do território e não o território em si mesmo, que faz dele objeto da análise social. Trata-se de uma forma impura, um híbrido, uma noção que, por isso mesmo, carece de constante revisão histórica. O que ele tem de permanente é ser nosso quadro de vida.

Seu entendimento é, pois, fundamental para afastar o risco de alienação, o risco da perda do sentido da existência individual e coletiva, o risco da renúncia ao futuro.

Para se compreender melhor o estudo de uma comunidade, torna-se necessário verificar como se dá a interação dos seres humanos no território, uma 
vez que a dinâmica espacial cria uma teia de relações que justificam sua realidade espaço-temporal. Assim, o sistema territorial é a lógica estrutural de um conjunto de espaços e lugares, onde a territorialidade é o atributo de um fato social em que circula o poder.

Por isso, a formação de uma identidade comunitária é um processo de construção social com base em atributos culturais (CASTELLS, 1997).

Assim, a territorialidade pode ser entendida como um "conjunto de relações que se originam num sistema tridimensional, sociedade, espaço e tempo em vias de atingir a maior autonomia possível e compatível com os recursos do sistema" (RAFFESTIN, 1993, p. 160). Albagli e Maciel (2004, p. 12) destacam que:

[...] a noção de territorialidade procura evidenciar a interface entre as dimensões, territorial e sociocultural, referindo-se às relações entre um indivíduo ou grupo social e seu meio de referência, manifestando-se nas várias escalas geográficas.

Na dimensão comunitária, as expressões dos atores sociais no momento de discussões, às vezes, a temporalidade escapa da análise imediata do discurso. Este em sua configuração aparece para interagir nos limites comunitários como uma experiência institucional. Tal organização deve sempre aparecer em forma de rede, em que as relações integram as representações constituídas no espaço territorial, formando, assim, uma territorialidade em que o agente principal é o próprio indivíduo que vive na comunidade (ROSENDAHL; CORRÊA, 2001, p. 52).

Preconiza-se que o território e a territorialidade inseridos no local tornam-se altamente complexos com múltiplos patamares e significados, em que a comunidade local repleta de culturas: simbolismos, mitos, ritos, danças, precisam ter uma interação de solidariedade, colocando o sentimento de pertença em evidência, objetivando uma endogenia para que a comunidade possa ser sustentável.

Entende-se ser imprescindível a contextualização da comunidade nesse contexto teórico, assim, percebe-se a comunidade como a forma de se estabelecer relações de troca, necessárias para o ser humano, de uma maneira mais íntima e marcada por contatos primários. Nas comunidades, as normas de convivência e de conduta de seus membros estão interligadas à tradição, religião, consenso e respeito mútuo, uma vez que o conceito de comunidade abrange um conjunto de pessoas unidas por interesses, hábitos ou opiniões comuns. Para Ávila (2001, p. 31): 
particular, mas um conjunto inteiro de interesses, suficientemente amplo e completo de modo a abranger suas vidas.

Como a ótica desta pesquisa tem foco na Comunidade da Região do Imbirussu, com enfoque nos Bairros Nova Campo Grande e Jardim Carioca na cidade de Campo Grande - MS, fez-se necessário destacar um referencial teórico acerca dos conceitos de Comunidade com o qual se está dialogando.

As comunidades surgem, organizam-se como resultantes dos processos de competição e de acomodação.

Segundo Palácios (1998), os elementos que caracterizariam essa comunidade são o sentimento de pertencimento, a territorialidade, a permanência, a ligação entre o sentimento de comunidade, caráter corporativo e emergência de um projeto comum, e a existência de formas próprias de comunicação. O sentimento de pertencimento, seria a noção de que o indivíduo é parte do todo, coopera para uma finalidade comum com os demais membros (caráter corporativo, sentimento de comunidade e projeto comum); a territorialidade, o lócus da comunidade; a permanência, condição essencial para o estabelecimento das relações sociais.

Acredita-se que para se abordar a Educação Popular, necessário se faz resgatar o sentido da própria educação e como ela está sendo tratada no Brasil.

A Constituição Federal Brasileira de 1988 foi um avanço no sentido de afirmação dos direitos sociais, dentre eles a educação. Esta lei magna aponta a educação como um direito de todos os cidadãos, onde o dever de provê-la é do Estado e da família, devendo ser incentivada pela sociedade como um todo, visando o pleno desenvolvimento da pessoa, seu preparo para o exercício da cidadania e sua qualificação para o trabalho. Portanto, pode-se afirmar que é por meio do conhecimento que o homem se apropria dos saberes produzidos e acumulados pela humanidade, para que ele exerça a sua cidadania.

Claude (2005, p.37) dimensiona que:

\begin{abstract}
A educação é um direito de múltiplas faces. É um direito social porque, no contexto da comunidade, promove o pleno desenvolvimento da personalidade humana; é um direito econômico, pois favorece a autosuficiência econômica por meio do emprego ou do trabalho autônomo; e é um direito cultural, já que a comunidade internacional orientou a educação no sentido de construir uma cultura universal de direitos humanos.
\end{abstract}

Cabe destacar que, segundo a Cartilha Direitos Humanos à Educação, ainda há muito a ser realizado em prol da educação, pois existe "muitas crianças, adolescentes, jovens e adultos fora da escola. Também são muitas as pessoas que 
desistem de estudar, que frequentam escolas sem a qualidade desejada e que vão à escola, mas não conseguem aprender" (RIZZI; GONZALES; XIMENES, 2009, p. 3).

$\mathrm{Na}$ busca por soluções capazes de reverter, ou ao menos minimizar, tal realidade, a Constituição Federal Brasileira de 1988 previu a criação de um Plano Nacional de Educação ${ }^{3}$ (PNE), aprovado por meio da Lei 10.172/01.

Identifica-se também na Lei de Diretrizes e Bases da Educação Nacional (LDB - Lei 9.394) de 1996, outro ganho para educação brasileira. Nesta Lei em seu artigo 214, parágrafo $2^{0}$ ressalta-se que: "a educação, é dever da família e do Estado, inspirada nos princípios de liberdade e nos ideais de solidariedade humana, tem por finalidade o pleno desenvolvimento do educando, seu preparo para o exercício da cidadania e sua qualificação para o trabalho".

A educação pode prover o bem-estar de toda uma nação, pois ela é capaz de reduzir desigualdades, especialmente com relação à renda. Ela faz parte de um conjunto de importantes indicadores que permitem mensurar o estágio de desenvolvimento humano da população.

Então, a educação popular além de estar intimamente relacionada à alfabetização de jovens e adultos e também à classe trabalhadora, tem caráter transformador, onde a escola e a sociedade são espaços legítimos da educação popular.

Freire (2003 apud MACIEL, 2011, p. 340), assinala que: a educação "é vista como fonte de produção do conhecimento altamente carregada de intencionalidade. Pela primeira vez se estabelece um vínculo entre educação e política, e educação e luta de classes".

A educação passa então a ser caracterizada como ato político que visa a formação humana em suas múltiplas potencialidades, cujo objetivo norteador é transformar o indivíduo em um sujeito integral. Ela revela um conteúdo firmado na realidade, adquirindo distintas modalidades de trabalho pedagógico expresso por um sistema aberto de ensino e aprendizagem

Com o intuito de mobilizar a sociedade para defender os interesses ambientais do planeta, e assim minimizar os impactos existentes e prevenir, ao máximo, os impactos posteriores, zelando pelo futuro da vida humana, o homem

\footnotetext{
${ }^{3}$ Art. 214. A lei estabelecerá o Plano Nacional de Educação, de duração plurianual, visando à articulação e ao desenvolvimento do ensino em seus diversos níveis e à integração das ações do Poder Público que conduzam à: I - erradicação do analfabetismo (BRASIL, 1988).
} 
aposta na criação de formas de proteger a natureza, fazendo surgir assim à educação ambiental.

De acordo com a Lei n 9.795, de 27 de abril de 1999:

Art. $1^{\circ}$ Entendem-se por educação ambiental os processos por meio dos quais 0 indivíduo e a coletividade constroem valores sociais, conhecimentos, habilidades, atitudes e competências voltadas para a conservação do meio ambiente, bem de uso comum do povo, essencial à sadia qualidade de vida e sua sustentabilidade.

Art. $2^{\circ} \mathrm{A}$ educação ambiental é um componente essencial e permanente da educação nacional, devendo estar presente, de forma articulada, em todos os níveis e modalidades do processo educativo, em caráter formal e nãoformal (BRASIL, 1999).

A referida lei expõe os objetivos e finalidades da Educação Ambiental e aponta uma intensa preocupação com a construção de atitudes e condutas compatíveis com a questão ambiental.

A escola tem a importante tarefa de fazer brotar o interesse pelo meio ambiente no indivíduo, independente do nível escolar do educando, seja por meio de propostas que apresentem conceitos e conhecimentos voltados para a preservação ambiental como também o uso sustentável dos recursos naturais. Para Loureiro (2008, p. 3):

\begin{abstract}
A Educação Ambiental é uma práxis educativa que se definiu no próprio processo de atuação, nas diferentes esferas da vida, das forças sociais identificadas com a questão ambiental. Estas, em suas múltiplas tendências, nas últimas três décadas, procuram materializar ações distintas e por vezes antagônicas, almejando alcançar patamares societários distintos do atual por meio de caminhos vistos como sustentáveis, requalificando a compreensão e o modo de nos relacionarmos na natureza.
\end{abstract}

Os conhecimentos, habilidades e atitudes adquiridas por meio da Educação Ambiental além de conscientizar os indivíduos, visam alavancar mudança de comportamento. Entretanto, cabe ressaltar que a questão ambiental está relacionada a todos os seres humanos e a tudo o que há na natureza, o que aponta para a complexidade existente no quesito Educação Ambiental.

Alguns sistemas normativos na ordem mundial, numa evolução que partiu do primeiro mundo, já haviam constitucionalizado as questões ambientais previamente ao Brasil.

A partir da Declaração de Estocolmo ${ }^{4}$ o mundo gradativamente foi tomando consciência da real necessidade de acordar para a problemática do meio ambiente,

\footnotetext{
4 Aprovada pelas Nações Unidas que se reuniu em Estocolmo em 1972, primeiro documento internacional que definiu 26 princípios na área ambiental.
} 
como a preservação da fauna, flora e espécies de animais, o combate a poluição das águas e atmosfera, entre outros, com o intuito de promover o desenvolvimento sustentável ${ }^{5}$.

A educação ambiental tende a proporcionar aos indivíduos à possibilidade de adquirir conhecimentos e criar atitudes voltadas a proteção do meio ambiente, mudando pensamentos e incentivando condutas capazes de promover a sua conservação e melhor utilização.

Nesse mundo globalizado não se poderia deixar de fora referências à tecnologia social, utilizada pelo Instituto de Tecnologia Social - Brasil e pela Fundação Banco do Brasil (FBB), destacando que

Tecnologia social é o conjunto de técnicas e metodologias transformadoras, desenvolvidas e/ou aplicadas na interação com a população e apropriadas por ela, que representam soluções para a inclusão social e melhoria das condições de vida (PICOLLO et al., 2011, p. 48.)

A Tecnologia Social tem a ver com as soluções criadas na interação com a população como resposta aos problemas que ela enfrenta, levando em conta suas tradições, seus arranjos organizacionais, os saberes locais, o potencial natural da região, enfim, sua realidade histórica, econômica, social e cultural.

A Tecnologia Social é principalmente um modo de fazer, um modo de produzir conhecimento, que presta atenção em valores como à participação e o aprendizado, a disseminação de informações e do conhecimento entre todas as partes envolvidas, a transformação das pessoas e da realidade social, entre outros aspectos, procurando caminhar para o desenvolvimento socioeconômico sustentável.

Soluções ajustadas às necessidades do bem estar social: uma rede de atores protagonistas recebe apoio de um conjunto de organizações com o propósito de promover as inovações tecnológicas sustentáveis. Enquanto as inovações em tecnologia tradicional das empresas têm sido guiadas pela competitividade individual e regras do mercado capitalista, a Tecnologia Social é guiada pela ampliação do campo de forças sociais locais (rede de interações) na busca de soluções tecnológicas ajustadas ao bem estar social e maior autonomia de decisões.

\footnotetext{
${ }^{5}$ O conceito de desenvolvimento sustentável surgiu no início da década de 1980, com a publicação, do documento Estratégia de Conservação Mundial: Conservação dos Recursos Vivos para o Desenvolvimento Sustentável (SIRVINSKAS, 2002).
} 
Atenção especial é creditada às respostas inovadoras e sinérgicas que emergem do território, visando à transformação social. As novas tecnologias voltamse à solução de problemas específicos de cada território, ajustadas ao conhecimento existente, mediado pela cultura.

A rede de cooperação se sustenta por uma forma de aprendizagem social (interativa), num diálogo entre saber tácito e explícito e a aprendizagem implica na interação entre sociedade civil, empresas e instituições locais.

Tem-se em vista a capacitação coletiva para promover soluções tecnológicas inovadoras passíveis de proporcionar soluções constantes e sustentáveis nas condições e ambientes de vida.

Na proposta de construção de saberes na prática das Tecnologias Sociais, é fundamental o entendimento de que o conhecimento tácito e o conhecimento explícito não são entidades totalmente separadas. Ambos constituem saberes mutuamente complementares.

Torna-se necessário contextualizar dois termos ligados à inovação: internalização - que são informações de sensibilização por meio de palestras (conhecimento explícito) que circulam com apoio de organizações; externalização são os alunos que aprendem pesquisando sobre seu território e externalizam o conhecimento à coletividade por meio da oralidade e da representação produzida da realidade.

\section{TECNOLOGIAS SOCIAIS: PENSAR, FAZER E INOVAR EM UMA COMUNIDADE ESCOLAR}

Apoiado nessas reflexões e em pressupostos teóricos apresenta-se a seguir a concretização exemplificadora de um Projeto Político Pedagógico - PPP, na comunidade educativa da Escola Municipal Prof. Fauze Gatass Filho, em Campo Grande, MS.

Pensou-se a construção de um Projeto Político Pedagógico que, partindo do respeito à realidade vivida pela comunidade circundante à escola, espaço sóciocultural de proveniência dos alunos que freqüentam a instituição educacional pública municipal, pudesse intervir sobre a mesma para produzir o seu desenvolvimento 
local, focando, sobretudo os valores da cidadania, ciência, cultura e respeito ao meio-ambiente.

O Projeto Político Pedagógico da Escola Municipal Prof. Fauze Gatass Filho construiu-se em torno do eixo fundamental constituído pelo Projeto: Amigos da Cidadania, da Cultura e do Meio Ambiente, que a partir de 2011 passou a ser denominado - Tecnologias Sociais: o Pensar, o Fazer e o Inovar na Comunidade

Escolar. Neste sentido, elencam-se a seguir as diversas fases e ações que integram o PPP nas suas metas mais recentes: algumas em franca execuções e outras em compasso de sistematização de parcerias e arranjo interinstitucional. Dentre elas destacam-se: - realização de um seminário com o tema: Projeto Político Pedagógico: Uma Ação Interinstitucional; implementação de estratégias e práticas participativas e interdisciplinares para a interação escola-comunidade de entorno, visando à articulação e troca de saberes (científico-popular); formação de horta escolar; organização de um Jornal Comunitário; sistematização de uma Rádio Escolar; realização de um processo de coleta de material reciclável, interação com os catadores da região; realização de Cursos, contribuindo para um amplo processo de educação continuada e permanente, abrangendo a comunidade escolar intra e extramuros escolares, em parceria com as Incubadoras Tecnológicas Municipais; realização de curso de extensão, com o tema: Formação de Agentes em Desenvolvimento Local em parceria com Universidades locais; realização de curso de alfabetização de jovens e adultos; realização de iniciação cientifica por parte de um grupo de alunos ( $8^{\circ}$ anos) em pesquisa sobre: "O homem Pantaneiro: Cultura, Ciência e Tecnologia, dos tempos de Sapicuá Pantaneiro aos tempos de CPU"; realização de oficinas sobre artesanato cultural pantaneiro (faixa pantaneira, argila, couro e outros), sobre a alimentação típica e também em metodologia de intervenções em arte e cultura em parceria com os Projetos: Sapicuá Pantaneiro e Arara Azul; organização de um Simpósio sobre a trajetória do Homem Pantaneiro: Cultura, Ciência e Tecnologia, dos tempos de Sapicuá Pantaneiro aos tempos de CPU.

Os resultados obtidos, até então, são de natureza quantitativa e/ou qualitativa; muitas vezes são proporcionais à qualidade do processo, embora existam outras atividades que nem mesmo foram mensuradas. Foi para enfrentar esse desafio que as atividades referentes ao processo de transformação social 
proporcionado na comunidade em pauta, pelo Projeto Politico-Pedagógico da Escola Municipal Prof. Fauze Scaff Gatass Filho, de Campo Grande/MS em articulação com Tecnologias Sociais, foram documentadas via fotografias, vídeos, folders, cartazes etc. Dentre outros resultados identificou-se que número de alunos da escola cresceu de 789 em 2008 para 1038 em 2012 verificando-se um sentimento coletivo de pertencimento na comunidade local e nos alunos, professores e funcionários da Escola Fauze Gattaz Filho. Constatou-se também que nas reuniões ocorridas entre a escola e a comunidade do entorno o número de participantes cresceu na ordem de $68 / \%$. Nos contatos com os catadores de lixo do entorno e realização de oficinas para este público, fez nascer a Cooperativa de Catadores na região.

A construção, execução e efetividade das ações desse projeto, na comunidade local - e em outras circunvizinhas de escolas que desejaram replicar a mesma metodologia, mereceram à equipe educadora, que programou a proposta de Interação com as Tecnologias Sociais, prêmios e reconhecimento em âmbito Regional e Nacional, tais como:

- Prêmio Construindo a Nação do Instituto da Cidadania São Paulo - SP-2009;

- Premio FINEP de Inovação em Tecnologia Social - 1ำ lugar - Região Centro Oeste-2010;

- Projeto selecionado e Finalista na Mostratec - 2011 e 2012 - Novo Hamburgo RS;

- Prêmio: Aprender e Ensinar Tecnologias Sociais 2012 FBB - Revista Fórum. O processo em pauta encontra-se em plena execução e desfruta as dores e alegrias de qualquer processo de transformação social, com certezas e ao mesmo tempo dúvidas e questionamentos.

Os atores integrantes da citada experiência acreditam que a implementação da ação coletiva para a transformação social de uma comunidade, por meio da Interação da Educação com as Tecnologias Sociais, exige compromisso e coragem para o enfrentamento dos desafios que permeiam esse processo.

Hoje, já com algum tempo na prática dessa interação, muitos dos envolvidos diretamente na experiência acreditam que o primeiro grande desafio a ser vencido, seja: enquanto educadores aprender a aprender no trabalho de interação e trocar de saberes com as comunidades para que com mais legitimidade se possa ensinar e construir os Projetos Políticos Pedagógicos das escolas brasileiras. 


\section{CONSIDERAÇÕES FINAIS}

Confirmou-se o entendimento de que a educação deve existir, hoje, mais do que nunca, nas possibilidades de construção de uma sociedade inclusiva e solidária, e para que isso aconteça, devem-se adotar perspectivas democráticas e participativas como premissas básicas. Esse "fazer diferenciado" requer uma ampliação no conjunto de atores que tomam as decisões em matéria educacional. Entretanto, embora seja possível reconhecer que existe hoje um arcabouço teórico e legal que favorece o processo de envolvimento dos diversos atores nas variadas instâncias do sistema educativo, o avanço nessa direção ainda é tímido, o que revela a dificuldade da implantação dessas medidas. Afinal, essas práticas participativas e democráticas, embora condição essencial, para que a Educação se reconstrua, também, ao mesmo tempo são práticas estranhas à trajetória histórica de constituição dos sistemas educativos. Tem-se consciência e clareza, de que este estranhamento histórico, não é algo fácil nem tranquilo de ser superado.

Muitos dirão, com certo desânimo, que a discussão dessas possibilidades não diz respeito ao âmbito do local e que remete a um projeto nacional de desenvolvimento. De fato, a mudança de escala das experiências locais inovadoras, que se criam no âmbito local, para políticas com impacto nacional, necessita de políticas nacionais que favoreçam e estimulem as iniciativas de desenvolvimento local.

Mesmo a ideia de um projeto nacional de desenvolvimento, para se assumir como prioridade na agenda da política nacional, precisa enfrentar a hegemonia do modelo neoliberal, que tem afetado essa possibilidade, afirmando o que se convencionou chamar de pensamento único, isto é, considerar que a única alternativa possível, em termos de modelo de desenvolvimento, é o modelo vigente.

\section{REFERÊNCIAS}

ALBAGLI, Sarita; MACIEL, Maria Lucia. Informação e conhecimento na inovação e no desenvolvimento local. Ciência e Informação, v. 33, n. 3. p. 9-16, set./dez., 2004. Disponível em: <http://www.scielo.br/pdf/ci/v33n3.pdf>. Acesso em: 16 mai. 2009. 
ÁVILA, V. F. de. Pressupostos para formação educacional em desenvolvimento local. Interações - Revista Internacional de Desenvolvimento Local, n. 1, p. 63-75, set. 2000.

ÁVILA, V. F. de et al. Formação educacional em desenvolvimento local: relato de estudo em grupo e análise de conceitos. 2. ed. Campo Grande-MS: UCDB, 2001.

BRASIL. Lei n 9.795, de 27 de abril de 1999. Dispõe sobre a educação ambiental, institui a Política Nacional de Educação Ambiental e dá outras providências.

Disponível em: <http://www.planalto.gov.br/ccivil_03/Leis/L9795.htm>. Acesso em: 22 jan. 2013.

. Constituição da República Federativa do Brasil de 1988. Brasília: Senado, 1988.

. Lei no. 9.394, de 20 de dezembro de 1996. Estabelece as diretrizes e bases da educação nacional. Disponível em: <http://www.

planalto.gov.br/ccivil_03/leis/19394.htm>. Acesso em: 21 de jan. de 2013.

CARLOS, A. F. O lugar no/do mundo. São Paulo: HUCITEC, 1996.

CASTELLS, M. O poder e identidade. Oxford: Blackwell, 1997, v. 2.

CLAUDE, R. P. Direito à educação e educação para direitos humanos. SUR:

Revista Internacional de Direitos Humanos. Ano 2, n. 2, 2005 p. 37-63, São Paulo:

Rede Universitária de Direitos Humanos.

LOUREIRO, Carlos Frederico B. Proposta pedagógica. Salto para o futuro educação ambiental no Brasil, Ano XVIII boletim 01 - Março de 2008.

MACIEL, Karen de Fátima. O pensamento de Paulo Freire na trajetória da educação popular. Educação em Perspectiva, Viçosa, v. 2, n. 2, p. 326-344, jul./dez. 2011.

NÓVOA, Antônio et al. Formação para o desenvolvimento. Lisboa: Fim de século/OIT, 1992.

PICCOLO, Aparecida Cristina Campello Curado; OLIVEIRA, Edilene Maria de; SILVA, Lucimara Nascimento da; GABARA, Nadia Sater; GUIMARÃES, Valdenir de Freitas. Aprendizagem interativa na construção dos saberes organizacionais e territoriais. Campo Grande: UCDB, 2011.

RAFFESTIN, C. Por uma geografia do poder. São Paulo: Ática. 1993.

RIZZI, E, GONZALEZ, M. XIMENES, S. Direito humano à educação. Coleção Cartilhas de Direitos Humanos. São Paulo: Plataforma Dhesca Brasil, v. 4, 2009.

ROSENDAHL, Z; CORRÊA, R. L. Religião, identidade e território. Rio de Janeiro: UERJ, 2001. 
SANTOS, B. de S. Introdução a uma ciência pós-moderna. Rio de Janeiro: Graal, 1989.

. (Org.). Democratizar a democracia: os caminhos da democracia participativa. Rio de Janeiro: Civilização Brasileira, 2002.

SIRVINSKAS, L. P. Manual de direito ambiental. São Paulo: Saraiva, 2002.

SOUZA, M. L. de. O território: sobre espaço e poder, autonomia e desenvolvimento. In: CASTRO, I.E. et al. (Orgs.). Geografia - conceitos e temas. Rio de Janeiro: Bertrand Brasil, 1995. 